Research Article

\title{
Research on Evaluation of Sustainable Development of New Urbanization from the Perspective of Urban Agglomeration under the Pythagorean Fuzzy Sets
}

\author{
Lingyan Meng $\mathbb{D}^{1}$ and Xiaoyan Wei $\mathbb{i D}^{2}$ \\ ${ }^{1}$ Department of Economics and Management, Jining University, Qufu 273115, Shandong, China \\ ${ }^{2}$ School of Economics and Law, University of Science and Technology Liaoning, Anshan 114051, Liaoning, China \\ Correspondence should be addressed to Xiaoyan Wei; wxylnkjdx59@ustl.edu.cn
}

Received 29 June 2021; Revised 9 July 2021; Accepted 30 July 2021; Published 17 August 2021

Academic Editor: Marek Galewski

Copyright (C) 2021 Lingyan Meng and Xiaoyan Wei. This is an open access article distributed under the Creative Commons Attribution License, which permits unrestricted use, distribution, and reproduction in any medium, provided the original work is properly cited.

In this study, considering the traditional geometric operation laws and Pythagorean fuzzy information, we propose a variety of new distance measures of Pythagorean fuzzy sets such as generalized Pythagorean fuzzy geometric distance (GPFGD) measures and generalized Pythagorean fuzzy weighted geometric distance (GPFWGD) measures. Besides, some special issues including Hamming distance, Euclidean distance, and Hausdorff distance of these raised geometric distance measures are investigated. To testify the valid of these new presented distance measures, we build a decision-making model illustrated by a mathematical calculation example to evaluate the sustainable development of new urbanization from the perspective of urban agglomeration using Pythagorean fuzzy information.

\section{Introduction}

The concept of the intuitionistic fuzzy set (IFS) is presented by Atanassov [1], which stretches the fuzzy set (FS) [2]. In the IFS, each number is represented by an ordered pair, which consists of two parts, membership $\mu$ and nonmembership $v$. The summation of the two does not exceeds 1 , which can be signified as $\mu+v \leq 1$ [3-7]. On the basis of the unipolar bivariate model, Chen [8] proposed an effective correlation model between optimism and pessimism of MCDM under the background of IFSs [9-13]. Chen [14] conducted a comparative study on the MCDM scoring function based on IFSs. By connecting anchor dependency and precision functions, Chen [15] conducted a beneficial research on MADM problems in IFSs. Xiao et al. [16] developed the intuitionistic fuzzy taxonomy method. In addition, the Pythagorean fuzzy set (PFS) [17] has come out as a valid MADM appliance to measure the indeterminancy and complexity of evaluation information. Zhang and $\mathrm{Xu}$ [18] constructed an extended model, called Pythagorean-
TOPSIS, to figure out the MADM problems. To better understand the PFS, Pythagorean fuzzy division operations and Pythagorean fuzzy subtraction operations came up first by Peng and Yang [19]. Some meritorious features of continuous Pythagorean fuzzy information are studied by Gou et al. [20]. Garg [21] presented a few novel Pythagorean fuzzy aggregation operators including the PFEWA operator, PFEOWA operator, GPFEWA operator, and GPFEOWA operator. Zeng et al. [22] took advantages of the PFOWAWAD operator to figure out MADM issues with Pythagorean fuzzy. Chen [23] defined a new PF-VIKOR method for MADM analysis. Bolturk [24] linked the CODAS method with Pythagorean fuzzy environment and built a new evaluation model. Liang et al. [25] came up with the fuzzy Bonferroni mean aggregation operator of Pythagorean theorem based on geometric mean (GM) operation. On the basis of PFSs, Garg [26] came up with a neutral operation of the MAGDM process based on the Pythagorean fuzzy set. Garg [27] defined a Pythagorean fuzzy geometric operator based on neutral operation for MAGDM issues. Molla 
et al.[28] defined the Pythagorean fuzzy PROMETHEE method. Deb and Roy [29] proposed the software defined network information security risk assessment based on PFSs. Verma and Merigo [30] defined the generalized similarity measures for PFSs. Chinram et al. [31] defined the new similarity and distance measures of PFSs. Zhao et al. [32] defined the TODIM method for interval-valued Pythagorean fuzzy MAGDM based on cumulative prospect theory. $\mathrm{He}$ et al. [33] defined the Pythagorean interval 2-tuple linguistic VIKOR method.

In previous works, some traditional distance measures such as the WHD measure, WED measure, and the WHHD measure have been investigated in the past decades [34-36]. Burillo and Bustince [37] determined the Hamming distance and the Euclidean distance between two IFNs. Then, to consider the uncertainty of membership, Szmidt and Kacprzyk [36] put forward some new distance measures of IFSs. By considering four parameters, the fuzzy distance measure of some Pythagorean theorems in MADM problem is proposed by Li and Zeng [38]. In addition, Zeng et al. [39] further defined some novel distance measures by taking five parameters into account under Pythagorean fuzzy environment. However, these developed distance measurements can only take into account the importance of each deviation value. In order to consider the ordered positions of computed distance measures, $\mathrm{Xu}$ and Chen [40] defined the OWD measure based on the OWA operator developed by Yager [41]. The most obvious feature of OWD measures is that they can be used to mitigate (or enhance) the impact of inappropriately large (or small) deviations on aggregate results by giving low (or high) weights. By expanding Xu and Chen' distance formula, Yager [42] put forward a few ordered weighted averaging norms and several similarity measures. Zeng [43] presented some OWD measures with intuitionistic fuzzy information including IFOWD measure and IFHWD measure. Afterwards, motivated by the OWG operator [44], Peng et al. [45] gave out some geometric distance measures based on IFNs. Then, Liu and Peng [46] extended the WGD measure, the OWGD measure, and the HWGD measure to interval-valued intuitionistic fuzzy sets (IVIFSs).

As far as the author knows, there is no research conducted based on geometric distance (GD) measures and Pythagorean fuzzy information [47-50] to apply in MADM problems, and so, it is meaningful to study this problem. Therefore, according to the Pythagorean fuzzy distance (PFD) measure and Pythagorean fuzzy Hausdorff distance (PFHD) measure, the objective of this study is to compute the distance between the alternatives and the optimal scheme by taking advantages of geometric algorithms. To that end, the rest of our article is as follows. Next part introduces a few traditional geometric distance measurements and the basic concepts of PFSs. In Section 3, GPFGD and GPFWGD are introduced, and a few special circumstances are studied. In Section 4, we will use the defined geometric distance measure to build the MADM problem model. In Section 5, we use Pythagorean fuzzy information to give a mathematical calculation example for evaluating the sustainable development of new urbanization from the perspective of urban agglomeration. Section 6 summarizes and comments the whole study.

\section{Preliminaries}

2.1. Some Geometric Distance Measures. In this section, consider both weighted distance (WD) and geometric operator; we briefly review some geometric distance (GD) measures defined by Peng et al. [45], which are listed as follows.

Definition 1. Given $A=\left(a_{1}, a_{2}, \ldots, a_{n}\right)$ and $B=\left(b_{1}, b_{2}, \ldots\right.$, $b_{n}$ ) are two groups of real numbers, the generalized geometric distance (GGD) between $A$ and $B$ can be represented as

$$
\mathrm{GGD}=\left(\prod_{i=1}^{n}\left(\left(d\left(a_{i}, b_{i}\right)\right)^{\beta}\right)^{1 / n}\right)^{1 / \beta}
$$

where $\beta>0$, and $d\left(a_{i}, b_{i}\right)=\left|a_{i}-b_{i}\right|$ denotes the distance measure of $a_{i}$ and $b_{i}$.

(i) If $\beta=1$, the generalized geometric distance (GGD) will reduce to the Hamming geometric distance (HGD) which are represented as

$$
\mathrm{HGD}=\prod_{i=1}^{n}\left(d\left(a_{i}, b_{i}\right)\right)^{1 / n} .
$$

(ii) If $\beta=2$, the generalized geometric distance (GGD) will reduce to the Euclidean geometric distance (EGD) which are represented as

$$
\mathrm{EGD}=\sqrt{\prod_{i=1}^{n}\left(\left(d\left(a_{i}, b_{i}\right)\right)^{2}\right)^{1 / n} .}
$$

Take the weighting vector of each element into account; some weighted geometric distance can be introduced as follows.

Definition 2 (see [45]). Given $A=\left(a_{1}, a_{2}, \ldots, a_{n}\right)$ and $B=$ $\left(b_{1}, b_{2}, \ldots, b_{n}\right)$ are two groups of real numbers, their weighting vector is $w=\left(w_{1}, w_{2}, \ldots, w_{n}\right)$, which satisfies $0 \leq w_{i} \leq 1, \sum_{i=1}^{n} w_{i}=1$; then, the generalized weighted geometric distance (GWGD) between $A$ and $B$ can be defined as

$$
\text { GWGD }=\left(\prod_{i=1}^{n}\left(\left(d\left(a_{i}, b_{i}\right)\right)^{\beta}\right)^{w_{i}}\right)^{1 / \beta},
$$

where $\beta>0$, and $d\left(a_{i}, b_{i}\right)=\left|a_{i}-b_{i}\right|$ denotes the distance measure of $a_{i}$ and $b_{i}$.

(i) If $\beta=1$, the generalized weighed geometric distance (GWGD) will reduce to the weighted Hamming geometric distance (WHGD) presented as 


$$
\mathrm{WHGD}=\prod_{i=1}^{n}\left(d\left(a_{i}, b_{i}\right)\right)^{w_{i}} \text {. }
$$

(ii) If $\beta=2$, the generalized weighed geometric distance (GWGD) will reduce to the weighed Euclidean geometric distance (WEGD) presented as

$$
\mathrm{WEGD}=\sqrt{\prod_{i=1}^{n}\left(\left(d\left(a_{i}, b_{i}\right)\right)^{2}\right)^{w_{i}}}
$$

2.2. Pythagorean Fuzzy Set. Some concepts of PFSs [17] are briefly reviewed in this section. On this basis, we come up with a new PFNs score, accuracy functions, and comparison method.

Definition 3 (see [17]). Assume that $X$ be a fixed set. A PFS has the following expression form.

$$
P=\left\{\left\langle x,\left(\mu_{P}(x), \nu_{P}(x)\right)\right\rangle \mid x \in X\right\},
$$

where $\mu_{P}: X \longrightarrow[0,1]$ is the degree of membership and $v_{P}: X \longrightarrow[0,1]$ is the degree of nonmembership of the element $x \in X$ to $P$; meanwhile, $\forall x \in X$, and the following conditions shall be met:

$$
\left(\mu_{p}(x)\right)^{2}+\left(v_{p}(x)\right)^{2} \leq 1 .
$$

Definition 4 (see [51]). Given $\tilde{a}=(\mu, \nu)$ is a PFN, a PFN' score function SF can be expressed as follows:

$$
\operatorname{SF}(\widetilde{a})=\frac{1}{2}\left(1+\mu^{2}-v^{2}\right), \quad S(\widetilde{a}) \in[0,1] .
$$

Definition 5 (see [20]). Given $\tilde{a}=(\mu, v)$ is a PFN, a PFN' accuracy function $\mathrm{AH}$ of a PFN can be expressed as follows:

$$
\mathrm{AH}(\widetilde{a})=\mu^{2}+v^{2}, \quad H(\widetilde{a}) \in[0,1] .
$$

It is applied to evaluate the accuracy degree of the PFN $\tilde{a}=(\mu, v)$, where $\operatorname{AH}(\widetilde{a}) \in[0,1]$. The larger the value of $\mathrm{AH}(\widetilde{a})$, the more the degree of accuracy of the PFN $\widetilde{a}$ is.

An order relation between two PFNs was given by Wei and $\mathrm{Lu} \mathrm{[51]}$ on the basis of the score function $S F$ and the accuracy function AH. It is expressed as follows.

Definition 6 (see [51]). Assume $\tilde{a}_{1}=\left(\mu_{1}, v_{1}\right)$ and $\tilde{a}_{2}=\left(\mu_{2}, v_{2}\right)$ be two PFNs. For $\widetilde{a}_{1}$, its scores function and accuracy function are, respectively, $\operatorname{SF}\left(\widetilde{a}_{1}\right)=1 / 2\left(1+\left(\mu_{1}\right)^{2}-\right.$ $\left.\left(\nu_{1}\right)^{2}\right)$ and $\operatorname{AH}\left(\tilde{a}_{1}\right)=\left(\mu_{1}\right)^{2}+\left(\nu_{1}\right)^{2}$. For $\tilde{a}_{2}$, its scores function and accuracy function are, respectively, $\operatorname{SF}\left(\widetilde{a}_{2}\right)=$ $1 / 2\left(1+\left(\mu_{2}\right)^{2}-\left(\nu_{2}\right)^{2}\right)$ and $\operatorname{AH}\left(\widetilde{a}_{2}\right)=\left(\mu_{2}\right)^{2}+\left(\nu_{2}\right)^{2}$; then, if $\operatorname{SF}\left(\widetilde{a}_{1}\right)<\operatorname{SF}\left(\widetilde{a}_{2}\right), \widetilde{a}_{1}$ is smaller than $\tilde{a}_{2}$, denoted by $\widetilde{a}<\tilde{b}$; $\operatorname{SF}(\widetilde{a})=\operatorname{SF}(\widetilde{b})$.

(1) If $\mathrm{AH}(\tilde{a})=\mathrm{AH}(\tilde{b})$, then $\tilde{a}$ is equal to $\tilde{b}$, denoted by $\widetilde{a}=\widetilde{b}$;
(2) If $\mathrm{AH}(\tilde{a})<\operatorname{AH}(\widetilde{b})$, then $\tilde{a}$ is smaller than $\tilde{b}$, denoted by $\tilde{a}<\widetilde{b}$.

Definition 7 (see [52]). Given $\tilde{a}_{1}=\left(\mu_{1}, v_{1}\right), \widetilde{a}_{2}=\left(\mu_{2}, v_{2}\right)$, and $\tilde{a}=(\mu, \nu)$ are three PFNS, some basic operations on them are defined as follows:
(1) $\tilde{a}_{1} \oplus \tilde{a}_{2}=\left(\sqrt{\left(\mu_{1}\right)^{2}+\left(\mu_{2}\right)^{2}-\left(\mu_{1}\right)^{2}\left(\mu_{2}\right)^{2}}, \nu_{1} \nu_{2}\right)$
(2) $\tilde{a}_{1} \otimes \tilde{a}_{2}=\left(\mu_{1} \mu_{2}, \sqrt{\left(\nu_{1}\right)^{2}+\left(\nu_{2}\right)^{2}-\left(\nu_{1}\right)^{2}\left(\nu_{2}\right)^{2}}\right)$
(3) $\lambda \widetilde{a}=\left(\sqrt{1-\left(1-\mu^{2}\right)^{\lambda}}, v^{\lambda}\right), \lambda>0$
(4) $(\tilde{a})^{\lambda}=\left(\mu^{\lambda}, \sqrt{1-\left(1-v^{2}\right)^{\lambda}}\right), \lambda>0$
(5) $\tilde{a}^{c}=(\nu, \mu)$

\section{Some Pythagorean Fuzzy Geometric Distance Measures}

Based on the GD measures and PFSs, we shall propose the GPFGD measures, the GPFHGD measures, and the GHPFGD in this section.

\subsection{Pythagorean Fuzzy Geometric Distance Measures}

Definition 8. Suppose that $A=\left(a_{1}, a_{2}, \ldots, a_{n}\right)$ and $B=\left(b_{1}, b_{2}, \ldots, b_{n}\right)$ be two groups of PFNs, the generalized Pythagorean fuzzy geometric distance (GPFGD) between $A$ and $B$ can be defined as

$$
d_{\mathrm{GPFD}}(A, B)=\left(\prod_{i=1}^{n}\left(\left(d_{\mathrm{PFD}}\left(a_{i}, b_{i}\right)\right)^{\beta}\right)^{1 / n}\right)^{1 / \beta},
$$

where $\beta>0$, and $d_{\mathrm{PFD}}\left(a_{i}, b_{i}\right)$ denotes the distance measure of two PFNs $a_{i}$ and $b_{i}$ which can be expressed as

$$
d_{\mathrm{PFD}}\left(a_{i}, b_{i}\right)=\frac{1}{2}\left(\left|\mu_{i}^{2}-\mu_{i}^{2}\right|+\left|v_{i}^{2}-v_{i}^{2}\right|\right)
$$

(i) If $\beta=1$, the generalized Pythagorean fuzzy geometric distance (GPFGD) will reduce to Pythagorean fuzzy Hamming geometric distance (PFHGD):

$$
d_{\mathrm{PFHGD}}(A, B)=\prod_{i=1}^{n}\left(d_{\mathrm{PFD}}\left(a_{i}, b_{i}\right)\right)^{1 / n} .
$$

(ii) If $\beta=2$, the generalized Pythagorean fuzzy geometric distance (GPFGD) will reduce to Pythagorean fuzzy Euclidean geometric distance (PFEGD):

$$
d_{\mathrm{PFEGD}}(A, B)=\sqrt{\prod_{i=1}^{n}\left(\left(d_{\mathrm{PFD}}\left(a_{i}, b_{i}\right)\right)^{2}\right)^{1 / n}} .
$$

Definition 9. Suppose that $A=\left(a_{1}, a_{2}, \ldots, a_{n}\right)$ and $B=\left(b_{1}, b_{2}, \ldots, b_{n}\right)$ be two groups of PFNs, the generalized Pythagorean fuzzy Hausdorff geometric distance (GPFHGD) between $A$ and $B$ can be defined as 


$$
d_{\mathrm{GPFHGD}}(A, B)=\left(\prod_{i=1}^{n}\left(\left(d_{\mathrm{PFHD}}\left(a_{i}, b_{i}\right)\right)^{\beta}\right)^{1 / n}\right)^{1 / \beta} .
$$

where $\lambda>0$, and $d_{\mathrm{PFHD}}\left(a_{i}, b_{i}\right)$ denotes the Hausdorff distance measure of two PFNs $a_{i}$ and $b_{i}$ which can be expressed as

$$
d_{\mathrm{PFHD}}\left(a_{i}, b_{i}\right)=\max _{j}\left(\left|\mu_{i}^{2}-\mu_{i}^{2}\right|,\left|v_{i}^{2}-v_{i}^{2}\right|\right) .
$$

(i) If $\beta=1$, the generalized Pythagorean fuzzy Hausdorff geometric distance (GPFHGD) will reduce to Pythagorean fuzzy Hamming-Hausdorff geometric distance (PFHHGD):

$$
d_{\mathrm{PFHHGD}}(A, B)=\prod_{i=1}^{n}\left(d_{\mathrm{PFHD}}\left(a_{i}, b_{i}\right)\right)^{1 / n} .
$$

(ii) If $\beta=2$, the generalized Pythagorean fuzzy Hausdorff geometric distance (GPFHGD) will reduce to Pythagorean fuzzy Euclidean-Hausdorff geometric distance (PFEHGD):

$$
d_{\mathrm{PFEHGD}}(A, B)=\sqrt{\prod_{i=1}^{n}\left(\left(d_{\mathrm{PFHD}}\left(a_{i}, b_{i}\right)\right)^{2}\right)^{1 / n}}
$$

Definition 10. Suppose that $A=\left(a_{1}, a_{2}, \ldots, a_{n}\right)$ and $B=\left(b_{1}, b_{2}, \ldots, b_{n}\right)$ be two groups of Pythagorean fuzzy numbers (PFNs), the generalized hybrid Pythagorean fuzzy geometric distance (GHPFGD) between $A$ and $B$ can be defined as

$$
d_{\mathrm{GHPFD}}(A, B)=\left(\prod_{i=1}^{n}\left(\frac{1}{2}\left(\left(d_{\mathrm{PFD}}\left(a_{i}, b_{i}\right)\right)^{\beta}+\left(d_{\mathrm{PFHD}}\left(a_{i}, b_{i}\right)\right)^{\beta}\right)\right)^{1 / n}\right)^{1 / \beta} .
$$

(i) If $\beta=1$, the generalized hybrid Pythagorean fuzzy geometric distance (GHPFGD) will reduce to hybrid Pythagorean fuzzy Hamming geometric distance (HPFHGD)

$d_{\mathrm{HPFHGD}}(A, B)=\prod_{i=1}^{n}\left(\frac{1}{2}\left(d_{\mathrm{PFD}}\left(a_{i}, b_{i}\right)+d_{\mathrm{PFHD}}\left(a_{i}, b_{i}\right)\right)\right)^{1 / n}$. (ii) If $\beta=2$, the generalized hybrid Pythagorean fuzzy geometric distance (GHPFGD) will reduce to hybrid Pythagorean fuzzy Euclidean geometric distance (HPFEGD):

$$
d_{\mathrm{HPFEG}}(A, B)=\sqrt{\prod_{i=1}^{n}\left(\frac{1}{2}\left(\left(d_{\mathrm{PFD}}\left(a_{i}, b_{i}\right)\right)^{2}+\left(d_{\mathrm{PFHD}}\left(a_{i}, b_{i}\right)\right)^{2}\right)\right)^{1 / n}} .
$$

In general, the above distance measures have the following properties:

(1) $0 \leq d(A, B) \leq 1$

(2) $d(A, B)=d(B, A)$

(3) $d(A, B)=0$, if and only if $A=B$

3.2. Pythagorean Fuzzy Weighted Geometric Distance Measures. Usually, $x_{i} \in X$, and it is important to take each element' weight into consideration; thus, in the following, we recommend the weighted geometric distance measures for Pythagorean fuzzy sets (PFSs) such as the generalized Pythagorean fuzzy weighted geometric distance (GPFWGD) measures, the generalized Pythagorean fuzzy weighted Hausdorff geometric distance (GPFHWGD) measures, and the generalized hybrid Pythagorean fuzzy weighted geometric distance (GHPFWGD) in this section.

Definition 11. Suppose that $A=\left(a_{1}, a_{2}, \ldots, a_{n}\right)$ and $B=\left(b_{1}, b_{2}, \ldots, b_{n}\right)$ be two groups of Pythagorean fuzzy numbers (PFNs) with the weighting vector be $w=\left(w_{1}, w_{2}, \ldots, w_{n}\right)$, which satisfies $0 \leq w_{i} \leq 1, \sum_{i=1}^{n} w_{i}=1$, then the GPFWGD between $A$ and $B$ can be defined as

$$
d_{\mathrm{GPFWG}}(A, B)=\left(\prod_{i=1}^{n}\left(\left(d_{\mathrm{PFD}}\left(a_{i}, b_{i}\right)\right)^{\beta}\right)^{w_{i}}\right)^{1 / \beta} .
$$


(i) If $\beta=1$, the generalized Pythagorean fuzzy weighted geometric distance (GPFWGD) will reduce to Pythagorean fuzzy weighted Hamming geometric distance (PFWHGD):

$$
d_{\mathrm{PFWHGD}}(A, B)=\prod_{i=1}^{n}\left(d_{\mathrm{PFD}}\left(a_{i}, b_{i}\right)\right)^{w_{i}} .
$$

(ii) If $\beta=2$, the generalized Pythagorean fuzzy weighted geometric distance (GPFWGD) will reduce to Pythagorean fuzzy weighted Euclidean geometric distance (PFWEGD):

$$
d_{\mathrm{PFWEGD}}(A, B)=\sqrt{\prod_{i=1}^{n}\left(\left(d_{\mathrm{PFD}}\left(a_{i}, b_{i}\right)\right)^{2}\right)^{w_{i}}} .
$$

Definition 12. Suppose that $A=\left(a_{1}, a_{2}, \ldots, a_{n}\right)$ and $B=\left(b_{1}, b_{2}, \ldots, b_{n}\right)$ be two groups of Pythagorean fuzzy numbers (PFNs) with the weighting vector be $w=\left(w_{1}, w_{2}, \ldots, w_{n}\right)$, which satisfies $0 \leq w_{i} \leq 1, \sum_{i=1}^{n} w_{i}=1$, then the GPFWGD between $A$ and $B$ can be defined as

$$
d_{\mathrm{GPFWHGD}}(A, B)=\left(\prod_{i=1}^{n}\left(\left(d_{\mathrm{PFHD}}\left(a_{i}, b_{i}\right)\right)^{\beta}\right)^{w_{i}}\right)^{1 / \beta} \text {. }
$$

(i) If $\beta=1$, the generalized Pythagorean fuzzy weighted Hausdorff geometric distance (GPFWHGD) will reduce to Pythagorean fuzzy weighted Hamming-Hausdorff geometric distance (PFWHHGD):

$$
d_{\mathrm{PFWHHGD}}(A, B)=\prod_{i=1}^{n}\left(d_{\mathrm{PFHD}}\left(a_{i}, b_{i}\right)\right)^{w_{i}}
$$

(ii) If $\beta=2$, the generalized Pythagorean fuzzy weighted Hausdorff geometric distance (GPFWHGD) will reduce to Pythagorean fuzzy weighted Euclidean-Hausdorff geometric distance (PFWEHGD):

$$
d_{\mathrm{PFWEHGD}}(A, B)=\sqrt{\prod_{i=1}^{n}\left(\left(d_{\mathrm{PFHD}}\left(a_{i}, b_{i}\right)\right)^{2}\right)^{w_{i}}}
$$

Definition 13. Suppose that $A=\left(a_{1}, a_{2}, \ldots, a_{n}\right)$ and $B=\left(b_{1}, b_{2}, \ldots, b_{n}\right)$ be two groups of Pythagorean fuzzy numbers (PFNs) with the weighting vector be $w=\left(w_{1}, w_{2}, \ldots, w_{n}\right)$, which satisfies $0 \leq w_{i} \leq 1, \sum_{i=1}^{n} w_{i}=1$, then the GHPFWGD between $A$ and $B$ can be defined as

$$
d_{\mathrm{GHPFWGD}}(A, B)=\left(\prod_{i=1}^{n}\left(\frac{1}{2}\left(\left(d_{\mathrm{PFD}}\left(a_{i}, b_{i}\right)\right)^{\beta}+\left(d_{\mathrm{PFHD}}\left(a_{i}, b_{i}\right)\right)^{\beta}\right)\right)^{w_{i}}\right)^{1 / \beta} .
$$

(i) If $\beta=1$, the generalized hybrid Pythagorean fuzzy weighted geometric distance (GHPFWGD) will reduce to hybrid Pythagorean fuzzy weighted Hamming geometric distance (HPFWHGD):

$$
d_{\mathrm{HPFWHGD}}(A, B)=\prod_{i=1}^{n}\left(\frac{1}{2}\left(d_{1}\left(a_{x_{i}}, b_{x_{i}}\right)+d_{2}\left(a_{x_{i}}, b_{x_{i}}\right)\right)\right)^{w_{i}} \text {. }
$$

(ii) If $\beta=2$, the generalized hybrid Pythagorean fuzzy weighted geometric distance (GHPFWGD) will reduce to hybrid Pythagorean fuzzy weighted Euclidean geometric distance (HPFWEGD):

$$
d_{\text {HPFWEGD }}(A, B)=\sqrt{\prod_{i=1}^{n}\left(\frac{1}{2}\left(\left(d_{1}\left(a_{x_{i}}, b_{x_{i}}\right)\right)^{2}+\left(d_{2}\left(a_{x_{i}}, b_{x_{i}}\right)\right)^{2}\right)\right)^{w_{i}}}
$$

Generally speaking, the weighted distance measurements have the following characteristics as well:
(1) $0 \leq d(A, B) \leq 1$
(2) $d(A, B)=d(B, A)$
(3) $d(A, B)=0$, if and only if $A=B$

\section{Model of MADM Problems Based on PFGD Measures}

Based the abovementioned Pythagorean fuzzy geometric distance measures, we shall present the MADM' model with Pythagorean fuzzy information. Suppose that $A=\left\{A_{1}, A_{2}, \ldots, A_{m}\right\} \quad$ be an alternatives group, $G=\left\{G_{1}, G_{2}, \ldots, G_{n}\right\}$ be an attributes group, their weighting vector is $w=\left(w_{1}, w_{2}, \ldots, w_{n}\right), w_{j} \in[0,1], \sum_{j=1}^{n} w_{j}=1$, and $d=\left\{d_{1}, d_{2}, \ldots, d_{\lambda}\right\}$ is an expert list, their weighting vector is $\varepsilon=\left(\varepsilon_{1}, \varepsilon_{2}, \ldots, \varepsilon_{\lambda}\right)$ which satisfies $\varepsilon_{j} \in[0,1], \sum_{j=1}^{\lambda} \varepsilon_{j}=1$. Construct the Pythagorean fuzzy evaluation matrix $R^{\lambda}=\left(r_{i j}^{\lambda}\right)_{m \times n}=\left(\mu_{i j}^{\lambda}, v_{i j}^{\lambda}\right)_{m \times n}$, where $\mu_{i j}^{\lambda} \in[0,1]$ indicates the extent to which the alternative $A_{i}$ satisfies the attributes $G_{j}$ given by the decision maker $d_{\lambda}$, and $v_{i j}^{\lambda} \in[0,1]$ indicates the extent that the alternative $A_{i}$ does not satisfy the attribute $G_{j}$ given by the decision maker $d_{\lambda}, \quad\left(\mu_{i j}^{\lambda}\right)^{2}+\left(v_{i j}^{\lambda}\right)^{2} \leq 1$, $i=1,2, \ldots, m, j=1,2, \ldots, n$. 
Step 1: we utilize the Pythagorean fuzzy weighted geometric (PFWG) operator to fuse information given in matrix $R^{\lambda}$, and the fused matrix $R=\left(r_{i j}\right)_{m \times n}$ can be denoted as follows.

$$
\begin{aligned}
r_{i j} & =\prod_{d=1}^{\lambda}\left(r_{i j}^{\lambda}\right)^{\varepsilon_{\lambda}}=\left(r_{i j}^{1}\right)^{\varepsilon_{1}} \otimes\left(r_{i j}^{2}\right)^{\varepsilon_{2}} \otimes \cdots \otimes\left(r_{i j}^{\lambda}\right)^{\varepsilon_{\lambda}} \\
& =\left\langle\prod_{d=1}^{\lambda}\left(\mu_{i j}^{\lambda}\right)^{\varepsilon_{\lambda}}, 1-\sqrt{\left.1-\prod_{d=1}^{\lambda}\left(1-\left(\mu_{i j}^{\lambda}\right)^{2}\right)^{\varepsilon_{\lambda}}\right\rangle, \quad i=1,2, \ldots, m, j=1,2, \ldots, n .}\right.
\end{aligned}
$$

Step 2: determine the best alternative $A^{+}$based on the fused results in equation (11) and get the Pythagorean fuzzy distance (PFD) and Pythagorean fuzzy Hausdorff distance (PFHD) by using equation (11)

$$
A_{1 \times n}^{+}=\left\{\left(\max _{i}\left(\mu_{i 1}\right), \min _{i}\left(v_{i 1}\right)\right),\left(\max _{i}\left(\mu_{i 2}\right), \min _{i}\left(v_{i 2}\right)\right), \ldots,\left(\max _{i}\left(\mu_{i n}\right), \min _{i}\left(v_{i n}\right)\right)\right\} .
$$

Step 3: utilize above defined Pythagorean fuzzy weighted geometric distance (PFWGD) to compute the distance between $A^{+}$and $A_{i}$

Step 4: sort all the alternatives $A_{i}(i=1,2, \ldots, m)$ and choose the best one based on the distance value. Obviously, the greater the distance value, the worse the alternative.

Step 5: end

\section{Illustrative Example}

Urbanization is the only way to develop social modernization and an important channel to accomplish the economic development of undeveloped countries or regions. Currently, the urbanization level in our country is in a stage of rapid development; however, in the past ten years, China's urbanization has followed such an extensive and denotative path as to cause its unsustainability during the development. To better and quicken China's urbanization, the notion of new-type urbanization is put forward in December 2015 at the City Work Meeting of the $18^{\text {th }}$ CPC National Congress, which explicitly shows that this kind of urbanization goes for the natural development rule. In detail, without any damage to the local natural surroundings, local urbanization is allowed to carry on. Only the preprotection of ecological environment can the local development turn to a sustainable path. In other words, the key point is to guarantee the constant natural protection of a local area throughout the whole urbanization. Therefore, the urbanization of different cities should be fulfilled on the premise of having nature protected all the way to accomplish its sustainable and healthy development. Urbanization is the current economic and social development situation and a sign of world development. New urbanization has developed rapidly in China in recent years. The national new urbanization plan proposes to take people's urbanization as the core and urban agglomeration as the main form and then to improve the level of urban sustainable development. The development model dominated by urban agglomerations is the dominant mode that China's urbanization must follow at this stage, and it is also an inevitable trend of urbanization development. In view of this, this study discusses the evaluation of sustainable development of new urbanization based on the theory associated with research. Therefore, to illustrate the method presented in this study, we will give a numericbased example for evaluating the sustainable development of new urbanization from the perspective of urban agglomeration using the Pythagorean fuzzy information in this part. Five applicable new urban centers $A_{i}(i=1,2,3,4,5)$ are considered. To evaluate the five applicable new urban centers by three experts $d_{\lambda}(\lambda=1,2,3)$, four attributes are given: (1) $G_{1}$ is the infrastructure; (2) $G_{2}$ is the urban-rural integration; (3) $G_{3}$ is the economic development; (4) $G_{4}$ is the resources and environment. The decision makers evaluate the five possible new urban centers $A_{i}(i=1,2,3,4,5)$ with the above four attributes anonymously in order to avoid mutual influence. The decision matrix $R^{\lambda}=\left(r_{i j}^{\lambda}\right)_{5 \times 4}$ is presented in Tables 1-3, where $r_{i j}^{\lambda}(i=1,2,3,4,5, j=1,2,3,4)$ are in the form of PFNs. The attributes' weight vector is $w=(0.16,0.28,0.36,0.20)^{T}$ and the experts' weighting vector is $\varepsilon=(0.35,0.40,0.25)$.

According to equation (31), we can obtain the fused matrix $R=\left(r_{i j}\right)_{5 \times 4}$ on the basis of the expert's weighting vector and information given in Tables $1-3$. The fused results are listed in Table 4.

Then, we can calculate the best alternative $A^{+}=\left(r_{j}^{+}\right)_{1 \times n}$ based on the fused results in Table 4 and equation (32). The computing results are listed as follows. 
TABLE 1: Pythagorean fuzzy information matrix $R^{1}$.

\begin{tabular}{lcclr}
\hline & $G_{1}$ & $G_{2}$ & $G_{3}$ & $G_{4}$ \\
\hline$A_{1}$ & $(0.6,0.7)$ & $(0.5,0.4)$ & $(0.3,0.6)$ & $(0.8,0.2)$ \\
$A_{2}$ & $(0.1,0.3)$ & $(0.4,0.5)$ & $(0.6,0.2)$ & $(0.5,0.1)$ \\
$A_{3}$ & $(0.7,0.4)$ & $(0.6,0.2)$ & $(0.8,0.5)$ & $(0.4,0.6)$ \\
$A_{4}$ & $(0.3,0.2)$ & $(0.5,0.1)$ & $(0.4,0.6)$ & $(0.2,0.5)$ \\
$A_{5}$ & $(0.3,0.1)$ & $(0.2,0.5)$ & $(0.4,0.2)$ & $(0.6,0.3)$ \\
\hline
\end{tabular}

TABLe 2: Pythagorean fuzzy information matrix $R^{2}$.

\begin{tabular}{lccll}
\hline & $G_{1}$ & $G_{2}$ & $G_{3}$ & $G_{4}$ \\
\hline$A_{1}$ & $(0.3,0.2)$ & $(0.2,0.7)$ & $(0.8,0.4)$ & $(0.5,0.3)$ \\
$A_{2}$ & $(0.4,0.2)$ & $(0.1,0.4)$ & $(0.5,0.4)$ & $(0.6,0.2)$ \\
$A_{3}$ & $(0.8,0.2)$ & $(0.4,0.7)$ & $(0.6,0.1)$ & $(0.5,0.2)$ \\
$A_{4}$ & $(0.4,0.3)$ & $(0.3,0.2)$ & $(0.5,0.1)$ & $(0.6,0.7)$ \\
$A_{5}$ & $(0.2,0.4)$ & $(0.5,0.3)$ & $(0.2,0.6)$ & $(0.7,0.4)$ \\
\hline
\end{tabular}

TABle 3: Pythagorean fuzzy information matrix $R^{3}$.

\begin{tabular}{lcccc}
\hline & $G_{1}$ & $G_{2}$ & $G_{3}$ & $G_{4}$ \\
\hline$A_{1}$ & $(0.3,0.6)$ & $(0.5,0.3)$ & $(0.1,0.5)$ & $(0.4,0.3)$ \\
$A_{2}$ & $(0.2,0.5)$ & $(0.5,0.4)$ & $(0.6,0.2)$ & $(0.4,0.6)$ \\
$A_{3}$ & $(0.6,0.5)$ & $(0.7,0.2)$ & $(0.5,0.2)$ & $(0.1,0.3)$ \\
$A_{4}$ & $(0.4,0.3)$ & $(0.5,0.2)$ & $(0.3,0.7)$ & $(0.4,0.6)$ \\
$A_{5}$ & $(0.6,0.2)$ & $(0.1,0.6)$ & $(0.3,0.6)$ & $(0.5,0.2)$ \\
\hline
\end{tabular}

TABle 4: Pythagorean fuzzy fusing information matrix $R$.

\begin{tabular}{lccrr}
\hline & $G_{1}$ & $G_{2}$ & $G_{3}$ & $G_{4}$ \\
\hline$A_{1}$ & $(0.3824,0.4479)$ & $(0.3466,0.4540)$ & $(0.3375,0.4925)$ & $(0.5574,0.7302)$ \\
$A_{2}$ & $(0.2071,0.6621)$ & $(0.2429,0.5611)$ & $(0.5578,0.7001)$ & $(0.5086,0.6491)$ \\
$A_{3}$ & $(0.7105,0.6276)$ & $(0.5302,0.4954)$ & $(0.6340,0.6705)$ & $(0.3092,0.5780)$ \\
$A_{4}$ & $(0.3617,0.7302)$ & $(0.4076,0.8279)$ & $(0.4070,0.4708)$ & $(0.3691,0.3818)$ \\
$A_{5}$ & $(0.3033,0.7170)$ & $(0.2426,0.5297)$ & $(0.2821,0.4877)$ & $(0.6097,0.6732)$ \\
\hline
\end{tabular}

$$
A^{+}=\{(0.7105,0.4479),(0.5302,0.4504),(0.6340,0.4708),(0.6097,0.3818)\}
$$

Next, we compute the Pythagorean fuzzy distance (PFD) and Pythagorean fuzzy Hausdorff distance (PFHD) by using equation (12) and equation (16). The computing results are listed as follows.

$$
\begin{aligned}
& d_{\mathrm{PFD}}\left(r_{11}, r_{1}^{+}\right)=0.1793, d_{\mathrm{PFD}}\left(r_{12}, r_{2}^{+}\right)=0.0805, d_{\mathrm{PFD}}\left(r_{13}, r_{3}^{+}\right)=0.1545, \\
& d_{\mathrm{PFD}}\left(r_{14}, r_{4}^{+}\right)=0.2242, d_{\mathrm{PFD}}\left(r_{21}, r_{1}^{+}\right)=0.3498, d_{\mathrm{PFD}}\left(r_{22}, r_{2}^{+}\right)=0.1654, \\
& d_{\mathrm{PFD}}\left(r_{23}, r_{3}^{+}\right)=0.1797, d_{\mathrm{PFD}}\left(r_{24}, r_{4}^{+}\right)=0.1943, d_{\mathrm{PFD}}\left(r_{31}, r_{1}^{+}\right)=0.0966, \\
& d_{\mathrm{PFD}}\left(r_{32}, r_{2}^{+}\right)=0.0197, d_{\mathrm{PFD}}\left(r_{33}, r_{3}^{+}\right)=0.1140, d_{\mathrm{PFD}}\left(r_{34}, r_{4}^{+}\right)=0.2322, \\
& d_{\mathrm{PFD}}\left(r_{41}, r_{1}^{+}\right)=0.3533, d_{\mathrm{PFD}}\left(r_{42}, r_{2}^{+}\right)=0.2972, d_{\mathrm{PFD}}\left(r_{43}, r_{3}^{+}\right)=0.1182, \\
& d_{\mathrm{PFD}}\left(r_{44}, r_{4}^{+}\right)=0.1178, d_{\mathrm{PFD}}\left(r_{51}, r_{1}^{+}\right)=0.3631, d_{\mathrm{PFD}}\left(r_{52}, r_{2}^{+}\right)=0.1483, \\
& d_{\mathrm{PFD}}\left(r_{53}, r_{3}^{+}\right)=0.1693, d_{\mathrm{PFD}}\left(r_{54}, r_{4}^{+}\right)=0.1537 .
\end{aligned}
$$




$$
\begin{aligned}
& d_{\mathrm{PFHD}}\left(r_{11}, r_{1}^{+}\right)=0.3586, d_{\mathrm{PFHD}}\left(r_{12}, r_{2}^{+}\right)=0.1610, d_{\mathrm{PFHD}}\left(r_{13}, r_{3}^{+}\right)=0.2881, \\
& d_{\mathrm{PFHD}}\left(r_{14}, r_{4}^{+}\right)=0.3874, d_{\mathrm{PFHD}}\left(r_{21}, r_{1}^{+}\right)=0.4619, d_{\mathrm{PFHD}}\left(r_{22}, r_{2}^{+}\right)=0.2221, \\
& d_{\mathrm{PFHD}}\left(r_{23}, r_{3}^{+}\right)=0.2685, d_{\mathrm{PFHD}}\left(r_{24}, r_{4}^{+}\right)=0.2755, d_{\mathrm{PFHD}}\left(r_{31}, r_{1}^{+}\right)=0.1933, \\
& d_{\mathrm{PFHD}}\left(r_{32}, r_{2}^{+}\right)=0.0393, d_{\mathrm{PFHD}}\left(r_{33}, r_{3}^{+}\right)=0.2279, d_{\mathrm{PFHD}}\left(r_{34}, r_{4}^{+}\right)=0.2761, \\
& d_{\mathrm{PFHD}}\left(r_{41}, r_{1}^{+}\right)=0.3740, d_{\mathrm{PFHD}}\left(r_{42}, r_{2}^{+}\right)=0.4793, d_{\mathrm{PFHD}}\left(r_{43}, r_{3}^{+}\right)=0.2363, \\
& d_{\mathrm{PFHD}}\left(r_{44}, r_{4}^{+}\right)=0.2355, d_{\mathrm{PFHD}}\left(r_{51}, r_{1}^{+}\right)=0.4128, d_{\mathrm{PFHD}}\left(r_{52}, r_{2}^{+}\right)=0.2223, \\
& d_{\mathrm{PFHD}}\left(r_{53}, r_{3}^{+}\right)=0.3224, d_{\mathrm{PFHD}}\left(r_{54}, r_{4}^{+}\right)=0.3074 .
\end{aligned}
$$

Case 1. Pythagorean fuzzy weighted Hamming geometric distance: suppose $\beta=1$, we use the PFWHGD measure, the PFWHHGD measure, and the HPFWHGD measure to compute the distances between each alternative and the ideal alternative and then the rank the alternatives as follows.

(1) Results obtained by PFWHGD measure are

$$
\begin{aligned}
& d_{\text {PFWHGD }}\left(A_{1}, A^{+}\right)=0.1420, d_{\text {PFWHGD }}\left(A_{2}, A^{+}\right)=0.1984, d_{\text {PFWHGD }}\left(A_{3}, A^{+}\right)=0.0782 \\
& d_{\text {PFWHGD }}\left(A_{4}, A^{+}\right)=0.1821, d_{\text {PFWHGD }}\left(A_{5}, A^{+}\right)=0.1808
\end{aligned}
$$

The rank of all the alternatives is $A_{3}>A_{1}>A_{5}>A_{4}>A_{2}$, and the best alternative is

(2) Results obtained by PFWHHGD measure are $A_{3}$.

$$
\begin{aligned}
& d_{\text {PFWHHGD }}\left(A_{1}, A^{+}\right)=0.2690, d_{\text {PFWHHGD }}\left(A_{2}, A^{+}\right)=0.2791, d_{\text {PFWHHGD }}\left(A_{3}, A^{+}\right)=0.1410, \\
& d_{\text {PFWHHGD }}\left(A_{4}, A^{+}\right)=0.3098, d_{\text {PFWHHGD }}\left(A_{5}, A^{+}\right)=0.2994 .
\end{aligned}
$$

The rank of all the alternatives is $A_{3}>A_{1}>A_{2}>A_{5}>A_{4}$, and the best alternative is (3) Results obtained by HPFWHGD measure are $A_{3}$.

$$
\begin{aligned}
& d_{\text {HPFWHGD }}\left(A_{1}, A^{+}\right)=0.2056, d_{\text {HPFWHGD }}\left(A_{2}, A^{+}\right)=0.2388, d_{\text {HPFWHGD }}\left(A_{3}, A^{+}\right)=0.1102, \\
& d_{\text {HPFWHGD }}\left(A_{4}, A^{+}\right)=0.2475, d_{\text {HPFWHGD }}\left(A_{5}, A^{+}\right)=0.2412 .
\end{aligned}
$$

The rank of all the alternatives is $A_{3}>A_{1}>A_{2}>A_{5}>A_{4}$, and the best alternative is $A_{3}$.

Case 2. Pythagorean fuzzy weighted geometric operator: according to the PFWG operator, we can aggregate the information in Table 4, and then, all the alternatives are sorted according to the PFNs' score and precision function, and the analysis results were as follows.

(4) Results obtained by the PFWG operator are

$$
\begin{aligned}
& r_{1}=(0.3835,0.5452), r_{2}=(0.3703,0.6061), r_{3}=(0.532,0.6579), \\
& r_{4}=(0.3918,0.719), r_{5}=(0.3192,0.7077) .
\end{aligned}
$$

Then, by score function, we can get 
TABLE 5: Evaluation results of these methods.

\begin{tabular}{lccc}
\hline Methods & Ranking order & The best alternative & The worst alternative \\
\hline SPFWA operator [53] & $A_{3}>A_{1}>A_{2}>A_{4}>A_{5}$ & $A_{3}$ & $A_{5}$ \\
SPFWG operator [53] & $A_{3}>A_{1}>A_{2}>A_{4}>A_{5}$ & $A_{3}$ & $A_{5}$ \\
PF-projection model [25] & $A_{3}>A_{1}>A_{2}>A_{4}>A_{5}$ & $A_{3}$ & $A_{5}$ \\
PF-TOPSIS method [18] & $A_{3}>A_{1}>A_{2}>A_{4}>A_{5}$ & $A_{3}$ & $A_{5}$ \\
PF-TODIM method [54] & $A_{3}>A_{1}>A_{2}>A_{4}>A_{5}$ & $A_{3}$ & $A_{5}$ \\
The developed method & $A_{3}>A_{1}>A_{2}>A_{4}>A_{5}$ & $A_{3}$ & $A_{5}$ \\
\hline
\end{tabular}

$$
s\left(A_{1}\right)=0.4249, s\left(A_{2}\right)=0.3849, s\left(A_{3}\right)=0.4251, s\left(A_{4}\right)=0.3183, s\left(A_{5}\right)=0.3006
$$

The rank of all the alternatives is $A_{3}>A_{1}>A_{2}>A_{4}>A_{5}$, and the optimal alternative is $A_{3}$.

\section{Compare Analysis}

In this section, our defined method is made comparison with some other methods to show its superiority.

Eventually, the results of these methods are in Table 5.

From Table 5, it is evident that the best alternative is $F_{3}$, while the worst alternative is $F_{1}$ in most situations. In other words, these methods' order is slightly different. Different methods can tackle MAGDM from different angles.

\section{Conclusion}

The sum of squares of membership and nonmembership less than or equal to 1 is a valuable property of the PFSs, and it can be used as a meaningful decision-making tool to deal with uncertainty of information. On the basis of the traditional Hamming distance, Euclidean distance, Hausdorff distance, and geometric distance, a variety of Pythagorean fuzzy geometric distance measurement methods are proposed. Then, taking the weighting vector of input arguments into account, we further investigate some PFWGD measures and illustrate some special cases. To address the MADM problems with PFSs more effectively, a decision model is established. Finally, we demonstrate the potential application through a numeric-based example about evaluating the sustainable development of new urbanization from the perspective of urban agglomeration to explain the approach presented in this study. In our future directions, we shall go on to apply the defined models and algorithms to other uncertain and fuzzy fields in the future [55-61] and apply these distance measures to interval-valued PFSs [62-68].

\section{Data Availability}

The data used to support the findings of this study are included in the article.

\section{Conflicts of Interest}

The authors declare that they have no conflicts of interest.

\section{References}

[1] K. T. Atanassov, "Intuitionistic fuzzy sets," Fuzzy Sets and Systems, vol. 20, no. 1, pp. 87-96, 1986.

[2] L. A. Zadeh, "Fuzzy sets," Information and Control, vol. 8, no. 3, pp. 338-353, 1965.

[3] M. Krawczak and G. Szkatuła, "On matching of intuitionistic fuzzy sets,” Information Sciences, vol. 517, pp. 254-274, 2020.

[4] J. Mahanta and S. Panda, "A novel distance measure for intuitionistic fuzzy sets with diverse applications," International Journal of Intelligent Systems, vol. 36, no. 2, pp. 615-627, 2021.

[5] R. Verma, "Generalized bonferroni mean operator for fuzzy number intuitionistic fuzzy sets and its application to multiattribute decision making," International Journal of Intelligent Systems, vol. 30, no. 5, pp. 499-519, 2015.

[6] R. Verma, "On intuitionistic fuzzy order- $\alpha$ divergence and entropy measures with MABAC method for multiple attribute group decision-making," Journal of Intelligent and Fuzzy Systems, vol. 40, pp. 1-27, 2020.

[7] M. Zhao, G. Wei, X. Chen, and Y. Wei, "Intuitionistic fuzzy MABAC method based on cumulative prospect theory for multiple attribute group decision making," International Journal of Intelligent Systems, 2021.

[8] T.-Y. Chen, "Bivariate models of optimism and pessimism in multi-criteria decision-making based on intuitionistic fuzzy sets," Information Sciences, vol. 181, no. 11, pp. 2139-2165, 2011.

[9] R. Verma and J. M. Merigó, “A new decision making method using interval-valued intuitionistic fuzzy cosine similarity measure based on the weighted reduced intuitionistic fuzzy sets," Informatica, vol. 31, pp. 399-433, 2020.

[10] R. Verma and B. D. Sharma, "Exponential entropy on intuitionistic fuzzy sets," Kybernetika, vol. 49, pp. 114-127, 2013.

[11] R. Verma and B. D. Sharma, "A new measure of inaccuracy with its application to multi-criteria decision making under intuitionistic fuzzy environment," Journal of Intelligent \& Fuzzy Systems, vol. 27, no. 4, pp. 1811-1824, 2014.

[12] S. Singh and H. Garg, "Distance measures between type-2 intuitionistic fuzzy sets and their application to multicriteria decision-making process," Applied Intelligence, vol. 46, no. 4, pp. 788-799, 2017.

[13] V. Singh and S. P. Yadav, "Development and optimization of unrestricted LR-type intuitionistic fuzzy mathematical programming problems," Expert Systems with Applications, vol. 80, pp. 147-161, 2017. 
[14] T.-Y. Chen, "A comparative analysis of score functions for multiple criteria decision making in intuitionistic fuzzy settings," Information Sciences, vol. 181, no. 17, pp. 3652-3676, 2011.

[15] T.-Y. Chen, "Experimental analysis of multi-attribute decision-making based on atanassov intuitionistic fuzzy sets: a discussion of anchor dependency and accuracy functions," International Journal of Systems Science, vol. 43, no. 6, pp. 1077-1103, 2012.

[16] L. Xiao, S. Zhang, G. Wei et al., "Green supplier selection in steel industry with intuitionistic fuzzy taxonomy method," Journal of Intelligent \& Fuzzy Systems, vol. 39, no. 5, pp. 7247-7258, 2020.

[17] R. R. Yager, "Pythagorean membership grades in multicriteria decision making," IEEE Transactions on Fuzzy Systems, vol. 22, no. 4, pp. 958-965, 2014.

[18] X. Zhang and Z. Xu, "Extension of TOPSIS to multiple criteria decision making with pythagorean fuzzy sets," International Journal of Intelligent Systems, vol. 29, no. 12, pp. 1061-1078, 2014.

[19] X. Peng and Y. Yang, "Some results for pythagorean fuzzy sets," International Journal of Intelligent Systems, vol. 30, no. 11, pp. 1133-1160, 2015.

[20] X. Gou, Z. Xu, and P. Ren, "The properties of continuous pythagorean fuzzy information," International Journal of Intelligent Systems, vol. 31, no. 5, pp. 401-424, 2016.

[21] H. Garg, "A new generalized pythagorean fuzzy information aggregation using Einstein operations and its application to decision making," International Journal of Intelligent Systems, vol. 31, no. 9, pp. 886-920, 2016.

[22] S. Zeng, J. Chen, and X. Li, "A hybrid method for pythagorean fuzzy multiple-criteria decision making," International Journal of Information Technology \& Decision Making, vol. 15, no. 2, pp. 403-422, 2016.

[23] T.-Y. Chen, "Remoteness index-based pythagorean fuzzy VIKOR methods with a generalized distance measure for multiple criteria decision analysis," Information Fusion, vol. 41, pp. 129-150, 2018.

[24] E. Bolturk, "Pythagorean fuzzy CODAS and its application to supplier selection in a manufacturing firm," Journal of Enterprise Information Management, vol. 31, no. 4, pp. 550-564, 2018.

[25] D. Liang, Z. Xu, and A. P. Darko, "Projection model for fusing the information of pythagorean fuzzy multicriteria group decision making based on geometric bonferroni mean," International Journal of Intelligent Systems, vol. 32, no. 9, pp. 966-987, 2017.

[26] H. Garg, "Neutrality operations based pythagorean fuzzy aggregation operators and its applications to multiple attribute group decision making process," Journal of Ambient Intelligence and Humanized Computing, vol. 11, no. 2, 2019.

[27] H. Garg, "Novel neutrality operation-based pythagorean fuzzy geometric aggregation operators for multiple attribute group decision analysis," International Journal of Intelligent Systems, vol. 34, no. 10, pp. 2459-2489, 2019.

[28] M. U. Molla, B. C. Giri, and P. Biswas, "Extended PROMETHEE method with pythagorean fuzzy sets for medical diagnosis problems," Soft Computing, vol. 25, no. 6, pp. 4503-4512, 2021.

[29] R. Deb and S. Roy, "A software defined network information security risk assessment based on pythagorean fuzzy sets," Expert Systems with Applications, vol. 183, Article ID 115383, 2021.
[30] R. Verma and J. M. Merigó, “On generalized similarity measures for pythagorean fuzzy sets and their applications to multiple attribute decision-making," International Journal of Intelligent Systems, vol. 34, no. 10, pp. 2556-2583, 2019.

[31] R. Chinram, A. Hussain, T. Mahmood, and M. I. Ali, "EDAS method for multi-criteria group decision making based on intuitionistic fuzzy rough aggregation operators," IEEE Access, vol. 9, pp. 10199-10216, 2021.

[32] M. Zhao, G. Wei, C. Wei, and J. Wu, "TODIM method for interval-valued pythagorean fuzzy MAGDM based on cumulative prospect theory and its application to green supplier selection," Arabian Journal for Science and Engineering, vol. 46, no. 2, pp. 1899-1910, 2021.

[33] T. T. He, G. W. Wei, R. Lin, J. P. Lu, C. Wei, and J. Wu, "Pythagorean interval 2-tuple linguistic VIKOR method for evaluating human factors in construction project management," Iranian Journal of Fuzzy Systems, vol. 17, pp. 93-105, 2020.

[34] Z. S. Xu and J. Chen, "An overview of distance and similarity measures of intuitionistic fuzzy sets," International Journal of Uncertainty, Fuzziness and Knowledge-Based Systems, vol. 16, no. 4, pp. 529-555, 2008.

[35] P. Grzegorzewski, "Distances between intuitionistic fuzzy sets and/or interval-valued fuzzy sets based on the hausdorff metric," Fuzzy Sets and Systems, vol. 148, no. 2, pp. 319-328, 2004.

[36] E. Szmidt and J. Kacprzyk, "Distances between intuitionistic fuzzy sets," Fuzzy Sets and Systems, vol. 114, no. 3, pp. 505-518, 2000.

[37] P. Burillo and H. Bustince, "Entropy on intuitionistic fuzzy sets and on interval-valued fuzzy sets," Fuzzy Sets and Systems, vol. 78, no. 3, pp. 305-316, 1996.

[38] D. Li and W. Zeng, "Distance measure of pythagorean fuzzy sets," International Journal of Intelligent Systems, vol. 33, no. 2, pp. 348-361, 2018.

[39] W. Zeng, D. Li, and Q. Yin, "Distance and similarity measures of pythagorean fuzzy sets and their applications to multiple criteria group decision making," International Journal of Intelligent Systems, vol. 33, no. 11, pp. 2236-2254, 2018.

[40] Z. Xu and J. Chen, "Ordered weighted distance measure," Journal of Systems Science and Systems Engineering, vol. 17, no. 4, pp. 432-445, 2008.

[41] R. R. Yager, "On ordered weighted averaging aggregation operators in multicriteria decision making," IEEE Transactions on Systems, Man, and Cybernetics, vol. 18, no. 1, pp. 183-190, 1988.

[42] R. R. Yager, "Norms induced from OWA operators," IEEE Transactions on Fuzzy Systems, vol. 18, no. 1, pp. 57-66, 2010.

[43] S. Zeng, "Some intuitionistic fuzzy weighted distance measures and their application to group decision making," Group Decision and Negotiation, vol. 22, no. 2, pp. 281-298, 2013.

[44] Z. S. Xu and Q. L. Da, "The ordered weighted geometric averaging operators," International Journal of Intelligent Systems, vol. 17, no. 7, pp. 709-716, 2002.

[45] B. Peng, C. Ye, and S. Zeng, "Some intuitionist fuzzy weighted geometric distance measures and their application to group decision making," International Journal of Uncertainty, Fuzziness and Knowledge-Based Systems, vol. 22, no. 5, pp. 699-715, 2014.

[46] C. Liu and B. Peng, "A method for group decision making based on interval-valued intuitionistic fuzzy geometric distance measures," Informatica, vol. 28, no. 3, pp. 453-470, 2017. 
[47] P. Mandal and A. S. Ranadive, "Decision-theoretic rough sets under pythagorean fuzzy information," International Journal of Intelligent Systems, vol. 33, no. 4, pp. 818-835, 2018.

[48] K. Rahman, A. Ali, S. Abdullah, and F. Amin, "Approaches to multi-attribute group decision making based on induced interval-valued pythagorean fuzzy Einstein aggregation operator," New Mathematics and Natural Computation, vol. 14, no. 3, pp. 343-361, 2018.

[49] K. Rahman, A. Ali, and M. S. A. Khan, "Some interval-valued pythagorean fuzzy weighted averaging aggregation operators and their application to multiple attribute decision making," Punjab University Journal of Mathematics, vol. 50, pp. 113129, 2018.

[50] M. Shakeel, S. Abdullah, M. S. A. Khan, and K. Rahman, "Averaging aggregation operators with interval pythagorean trapezoidal fuzzy numbers and their application to group decision making," Punjab University Journal of Mathematics, vol. 50, pp. 147-170, 2018.

[51] G. Wei and M. Lu, "Pythagorean fuzzy maclaurin symmetric mean operators in multiple attribute decision making," International Journal of Intelligent Systems, vol. 33, no. 5, pp. 1043-1070, 2018.

[52] M. Z. Reformat and R. R. Yager, "Suggesting recommendations using pythagorean fuzzy sets illustrated using netflix movie data," in Proceedings of the International Conference on Information Processing and Management of Uncertainty in Knowledge-Based Systems, pp. 546-556, Berlin, Germany, July 2014.

[53] Z. Ma and Z. Xu, "Symmetric pythagorean fuzzy weighted geometric/averaging operators and their application in multicriteria decision-making problems," International Journal of Intelligent Systems, vol. 31, no. 12, pp. 1198-1219, 2016.

[54] P. Ren, Z. Xu, and X. Gou, "Pythagorean fuzzy TODIM approach to multi-criteria decision making," Applied Soft Computing, vol. 42, pp. 246-259, 2016.

[55] S. Meysam Mousavi, J. Antuchevičienė, E. K. Zavadskas, B. Vahdani, and H. Hashemi, "A new decision model for cross-docking center location in logistics networks under interval-valued intuitionistic fuzzy uncertainty," Transport, vol. 34, no. 1, pp. 30-40, 2019.

[56] F. Lei, G. Wei, J. Wu, C. Wei, and Y. Guo, "QUALIFLEX method for MAGDM with probabilistic uncertain linguistic information and its application to green supplier selection," Journal of Intelligent \& Fuzzy Systems, vol. 39, no. 5, pp. 6819-6831, 2020.

[57] N. Liao, G. Wei, and X. Chen, "TODIM method based on cumulative prospect theory for multiple attributes group decision making under probabilistic hesitant fuzzy setting," International Journal of Fuzzy Systems, 2021.

[58] L. Liu, J. Wu, G. Wei, C. Wei, J. Wang, and Y. Wei, "Entropybased GLDS method for social capital selection of a PPP project with q-rung orthopair fuzzy information," Entropy, vol. 22, no. 4, p. 414, 2020.

[59] D. Stanujkic, D. Karabasevic, E. K. Zavadskas, F. Smarandache, and F. Cavallaro, "An approach to determining customer satisfaction in traditional Serbian restaurants," Entrepreneurship and Sustainability Issues, vol. 6, no. 3, pp. 1127-1138, 2019.

[60] Y. Huang, R. Lin, and X. Chen, "An enhancement EDAS method based on prospect theory," Technological and Economic Development of Economy, 2021.

[61] Y. Su, M. Zhao, C. Wei, and X. Chen, "PT-TODIM method for probabilistic linguistic MAGDM and application to industrial control system security supplier selection," International Journal of Fuzzy Systems, 2021.

[62] H. Garg, "A novel accuracy function under interval-valued pythagorean fuzzy environment for solving multicriteria decision making problem," Journal of Intelligent \& Fuzzy Systems, vol. 31, no. 1, pp. 529-540, 2016.

[63] X. Zhang, "Multicriteria pythagorean fuzzy decision analysis: a hierarchical QUALIFLEX approach with the closeness index-based ranking methods," Information Sciences, vol. 330, pp. 104-124, 2016.

[64] Y. He, G. Wei, and X. Chen, "Bidirectional projection method for multi-attribute group decision making under probabilistic uncertain linguistic environment," Journal of Intelligent \& Fuzzy Systems, 2021.

[65] W. Liang, X. L. Zhang, and M. F. Liu, "The maximizing deviation method based on interval-valued pythagorean fuzzy weighted aggregating operator for multiple criteria group decision analysis," Discrete Dynamics in Nature and Society, vol. 2015, Article ID 746572, 15 pages, 2015.

[66] G. Wei, C. Wei, J. Wu, and Y. Guo, "Probabilistic linguistic multiple attribute group decision making for location planning of electric vehicle charging stations based on the generalized dice similarity measures," Artificial Intelligence Review, vol. 54, no. 6, pp. 4137-4167, 2021.

[67] Y. Du, F. Hou, W. Zafar, Q. Yu, and Y. Zhai, "A novel method for multiattribute decision making with interval-valued pythagorean fuzzy linguistic information," International Journal of Intelligent Systems, vol. 32, no. 10, pp. 1085-1112, 2017.

[68] H. Garg, "A new improved score function of an intervalvalued pythagorean fuzzy set based topsis method," International Journal for Uncertainty Quantification, vol. 7, no. 5, pp. 463-474, 2017. 